\title{
Video Juego Interactivo Mediante SDK Kinect 1.6 para Apoyar la Educación Básica Primaria de Niños Entre 5 a 10 Años de Edad
}

\author{
Interactive Video Game Using Sdk Kinect 1.6 To Support \\ The Primary Basic Education Of Children Between \\ 5 To 10 Years Of Age
}

\section{Julián Humberto Tangarife, ${ }^{2}$ Yuri Vanessa Nieto Acevedo}

\author{
Corporación Unificada Nacional de Educación Superior C.U.N. \\ Departamento de Ingeniería de Sistemas \\ Bogotá D.C., Colombia \\ ${ }^{1}$ julian.tangarife@cun.edu.co ${ }^{2}$ yuri_nieto@cun.edu.co
}

\section{RESUMEN}

Teniendo en cuenta que hoy en día, la deserción escolar se ha convertido en uno de los principales problemas en Colombia, el objetivo de este artículo es presentar una nueva herramienta tecnológica que apoye a profesores y padres de familia en la formación integral de los niños tanto en la escuela como en el hogar [3]. Por lo anterior, se creó un videojuego interactivo, que estimula al niño a realizar una actividad muy sencilla en el área de matemáticas, la cual consiste en contar por medio del dispositivo Kinect mediante el movimiento de sus manos; estas permiten movilizar un número concreto de esferas solicitadas a un área seleccionada de la pantalla y, así mismo, verificar la cantidad e informar por medio de una ventana emergente si esta es correcta o si se debe realizar un nuevo intento. El proyecto queda abierto a mejoras, que permitan adicionar nuevas actividades referentes a las áreas del conocimiento humano, con el único fin de generar motivación por la educación en la infancia colombiana [3].

Palabras clave: diagrama de procesos, educación infantil, interacción humano computadora, meta proceso, desarrollo de software, SDK Kinect, XNA framework. 


\section{Abstract}

Taking into account that today, the school dropout rate has become one of the main problems in Colombia, the objective of this article is to present a new technological tool to support teachers and parents in the integral formation of children both, at school and at home [3]. Therefore, it was created an interactive video game, which stimulates the child to perform an activity very simple in the area of math, which consists of counting by means of the Kinect device through the movement of their hands; these allow to mobilize a concrete number of spheres requested to a chosen area of the screen and, likewise, to verify the quantity and to inform by means of an emergent window if this one is correct, or if it is necessary to make a new attempt. The project is open to improvements that allow adding new activities relating to the areas of human knowledge, with the sole purpose of generating motivation for Colombian children education [3].

Key words: early childhood education, human computer interaction, process diagram, process goal, SDK Kinect, software development, XNA framework.

\section{InTRODUCCIÓN}

El siglo XXI ha generado múltiples desafíos para las naciones del mundo, en especial, aquellas que quieren superar los rezagos en materia de desarrollo y crecimiento económico. La globalización nos ha impuesto a todos nuevas formas de relación en mercados abiertos y competitivos, así como la producción de bienes y servicios cada vez más complejos y sofisticados, que no solo agreguen valor sino también impongan su sello de identidad con relación a los demás países [1].

Colombia es un país que tiene una historia ligada a diferentes conflictos sociales internos, entre otros, el desplazamiento forzado por grupos armados, problema que afecta gravemente la educación de niños en la primera y segunda infancia $y$, por supuesto, también la de la juventud y la familia como núcleo principal del desarrollo del ser humano.

Es claro que el desplazamiento forzado genera que los niños pierdan las oportunidades que el gobierno les brinda para su desarrollo educativo en escuelas y colegios públicos; no obstante, este no es el único motivo de deserción escolar. La falta de recursos en el núcleo familiar, problemas de drogadicción, pandillas, bulling (uno de los más comunes actualmente).... hacen parte, igualmente, de esta problemática colombiana.

Este crecimiento en la deserción escolar es preocupante, y las estadísticas del DANE (Departamento Administrativo Nacional de Estadística) lo comprueban [2], pues se afecta el desarrollo futuro del país y además desencadena nuevos problemas como la delincuencia, drogadicción, indigencia, etc. Es así como el gobierno colombiano propone planes para mejorar la educación y llegar a diferentes regiones del país con diferentes proyectos, entre otros, la jornada única, el cual pretende fortalecer las competencias básicas y alejar a los niños y jóvenes de situaciones amenazantes para sus proyectos de vida.

Con la llegada del nuevo milenio, se abrieron las puertas de manera definitiva al conocimiento, al manejo de la información y al uso de las nuevas tecnologías, lo que exige una forma de pensar 
sobre el desarrollo individual y social, y una visión amplia acerca de las posibilidades de los seres humanos para transformar su propia realidad y potenciar sus capacidades hacia el futuro, a fin de lograr el bienestar y la prosperidad colectiva [1].

Esta nueva realidad determina la necesidad de desarrollar habilidades que son comunes a todas las personas. Pero también, pone al orden del día la necesidad de fortalecer la singularidad, la diferencia y la identidad cultural. La respuesta a este planteamiento está en la capacidad que tenga el país para desarrollar a plenitud el potencial y la creatividad de cada persona como ser humano, como ciudadano y como fuente de bienestar, desarrollo e innovación. Así mismo, en la capacidad que tenga para hacer de los talentos colectivos la principal herramienta para la competitividad. En este sentido, el principal y más grande desafío es la formación del capital humano [1].

Pensando en este fin, nace el proyecto de apoyar la educación de la infancia colombiana con medios tecnológicos que actualmente atraen la atención de niños y adultos; así se desarrolla un video juego educativo que contiene inicialmente un juego relacionado con las matemáticas, por medio del cual se le enseña a contar a los niños de forma didáctica, haciendo uso del dispositivo Kinect creado por Microsoft [3].

Este artículo se encuentra organizado de la siguiente forma: inicialmente, se hace la presentación del fundamento teórico, como base fundamental para entender por qué nace la necesidad de desarrollar una nueva herramienta tecnológica que funcione como apoyo a la educación infantil colombiana, utilizando para ello los videojuegos. Luego, se tiene una sección con antecedentes de algunos de los videojuegos educativos existentes y sus características más destacadas. La tercera sección contiene la metodología que se aplicó para el desarrollo del videojuego con base en las necesidades observadas en la investigación. En la cuarta, se presentan los resultados obtenidos después del desarrollo con las herramientas tecnológicas seleccionadas. Y, finalmente, las conclusiones a las que se llegó y el trabajo futuro que permita ampliar las funcionalidades del videojuego.

\section{Videojuegos en la Infancia}

[4] manifiestan que "la psicología del desarrollo tiene como fines primordiales la descripción, la explicación y la predicción de la conducta humana, y de manera más especial, el crecimiento y el desarrollo de la conducta humana". Afirman, además, que el desarrollo que ocurre a edad temprana afecta la conducta posterior. De ahí, la importancia de los trabajos que se realicen desde la perspectiva pedagógica, social e investigativa. Esta afirmación es generalmente aceptada y compartida por psicólogos y pedagogos, independientemente de las tendencias, teorías y escuelas a las que se adscriben. Sin embargo, a pesar de ese reconocimiento, fundamentado en investigaciones científicas y en la experiencia práctica-pedagógica sobre la importancia del trabajo con los niños a temprana edad, las decisiones y políticas de los países sobre educación y muy específicamente en Colombia sobre la atención educativa de los niños y niñas en estas edades, a la fecha no han sido claras y permanentes a través de un plan de gobierno.

Es aquí donde la tecnología ofrece herramientas que sirven como apoyo a la educación clásica impartida en hogares y centros educativos a la primera y segunda infancia. Se desarrolla con este fin un video juego interactivo, que utiliza la tecnología creada por Microsoft, Ilamada Kinect, utilizando herramientas como Visual Studio bajo lenguaje C\#, XNA Framework 4.0, SDK Kinect 1.6, Autodesk 3DS MAX 2016, Photoshop CS y el Dispositivo Kinect 1.0.

Su fin, apoyar el proceso de aprendizaje de los niños entre 5 y 10 años de edad, en lo referente a la asignatura básica de Matemáticas, con el ánimo de 
que los niños participen activamente en una tarea concreta como lo es mover una cantidad determinada de esferas solicitadas en pantalla, a un área representada con una imagen delimitante. Un juego bastante sencillo, que ayuda con el aprendizaje básico de contar [3].

La razón por la cual los videojuegos son una excelente forma de enseñar, es lo que en psicología se denomina "factores dinamizadores de nuestra conducta“. En palabras más sencillas de entender, los videojuegos poseen el atractivo de despertar la motivación para que niños y jóvenes se sientan conectados a su dinámica interna. Esta dinámica incluye un carácter lúdico y entretenido, junto a una alta estimulación auditiva, kinestésica, visual...etc., así como la incorporación de niveles de dificultad progresivos y graduales que requieren el dominio de los anteriores.

A continuación se brinda una sinopsis de las herramientas mencionadas anteriormente para el desarrollo del videojuego educativo:

\section{A. Hardware}

1) Ordenador: las especificaciones mínimasrecomendadas por Microsoft son un PC con procesador Dual Core $3.1 \mathrm{GHz}$ a 64 Bit, puertos USB 3.0 y 4 GB de RAM. Sistema operativo Windows 8.1 o 10. Tarjeta gráfica que admita Shader Model 2.0.

2) Sensor Kinect 1.0: primera versión del periférico desarrollado para la consola Xbox 360 y compatible con Windows 8.1 y 10. Es un dispositivo que hará olvidar completamente el uso de controles para interaccionar con los juegos o el propio ordenador; simplemente se utilizará el propio cuerpo para comunicar y mostrar las acciones que se deben realizar.

3) Adaptador de Kinect 1.0 para Windows: es un adaptador que permite realizar la adaptación del dispositivo Kinect 1.0 fabricado para Xbox 360, al PC por medio de un puerto USB 3.0

\section{B. Software}

1) SDK Kinect 1.6: librería oficial de Microsoft para el desarrollo de aplicaciones con el sensor Kinect 1.0. Incluye drivers y documentación técnica, APIs de referencia y ejemplos para las buenas prácticas de desarrollo con el sensor.

2) Visual Studio 2010: es un conjunto completo de herramientas de desarrollo para la generación de aplicaciones web ASP.NET, servicios Web XML, aplicaciones de escritorio y aplicaciones móviles. Visual Basic, Visual C\# y Visual C++ utilizan todos el mismo entorno de desarrollo integrado (IDE) que habilita el uso compartido de herramientas y facilita la creación de soluciones en varios lenguajes.

3) C\#: lenguaje de programación visual, controlado por eventos, en el cual se crean programas mediante el uso de un Entorno de Desarrollo Integrado (IDE). Mediante este IDE, el programador podrá crear, ejecutar, probar y depurar programas en C\#.

4) Autodesk 3D Max 2016: es uno de los programas de animación 3D más utilizados. Dispone de una sólida capacidad de edición, una omnipresente arquitectura de plugins y una larga tradición en plataformas Microsoft Windows. Lo desarrolladores de videojuegos utilizan, por lo general, 3ds Max, el mismo que se utiliza para películas o anuncios de televisión, efectos especiales y en arquitectura.

5) Photoshop CS: editor de gráficos rasterizados desarrollado por Adobe Systems Incorporated, usado principalmente para el retoque de fotografías y gráficos. Su nombre en español significa literalmente "taller de fotos".

6) XNA Framework 4.0: permite a estudiantes y aficionados la creación de videojuegos mediante el lenguaje de programación C\# sobre Windows, Xbox 360 y el reproductor de mp3 Zune. Uno de los objetivos es el desarrollo de juegos que corran sobre varias plataformas (PC, Xbox, Zune) de una 
forma sencilla. La idea se centró en crear un juego para Windows y rápidamente poder crear la versión para Xbox 360. En algunos casos habrá que diferenciar sobre varias plataformas, pero el concepto era tener alrededor de un $95 \%$ del comportamiento normalizado en un conjunto de APIs.

Es muy importante iniciar el desarrollo teniendo en cuenta la interacción que el usuario realizará con el dispositivo Kinect, la PC y sus periféricos. Es lo que se conoce como la interacción humano computadora.

El grupo especial de trabajo en temas de interacción humano computadora denominado SIG$\mathrm{CHI}$, Special Interest Group in Computer Human Interaction, define la IHC como: "Disciplina relacionada con el diseño, la evaluación e implementación de sistemas informáticos interactivos para el uso de los seres humanos, y con el estudio de los fenómenos más importantes con los que está relacionado" [5].

Además, se encarga de estudiar todo lo que tiene que ver con hardware y software y el efecto de ambos dentro de la interacción, los modelos mentales de los usuarios frente al sistema con el cual interactúan, las tareas que desempeña el sistema y su adaptación a necesidades de los destinatarios, el diseño dirigido y centrado en los usuarios, no en la PC, así como, el impacto organizacional.

En general, un sistema interactivo se crea conforme a los requerimientos de los usuarios, puesto que durante todas las fases de desarrollo del sistema se obtiene información relevante que permite diseñar una interfaz cercana a sus capacidades físicas y cognitivas y a sus gustos y expectativas [6].

La importancia del diseño nos lleva a la correcta creación de interfaces puesto que, en la mayoría de los casos, es el componente más crítico del sistema. Usuarios y operadores, generalmente, no entienden acerca del mundo interno de los ordena- dores compuestos por bits, bytes, ficheros, circuitos, etc.: es decir, conocen el sistema solamente a través de su interfaz, el texto, las imágenes o los sonidos que aparecen en los dispositivos de salida de dicho sistema (pantalla, altavoces. . .). En el mundo de los ordenadores para el usuario: "La interfaz es el sistema" [5].

\section{Juegos Educativos Alternos Bajo Kinect}

En los antecedentes se encontraron algunos juegos educativos desarrollados para los niños, entre los cuales los más relevantes son:

\section{A. Kinect Sesame Street}

Los niños están invitados a experimentar el fantástico y divertido mundo de Plaza Sésamo con sus personajes favoritos, como el gran pájaro Elefancio, Cuernos, Lola, Elmo, entre otros, como nunca antes se habían visto. La magia de Kinect para Xbox 360 brinda la oportunidad de compartir la experiencia visual e interactuar físicamente con los personajes, adentrando al niño en el mundo de Plaza Sésamo.

\section{B. Kinect Nat Geo TV}

El videojuego está distribuido en dos discos que contienen la primera "estación" de Nat Geo para Kinect TV o América the wild (la salvaje América) dirigido por el especialista en osos pardos de la National Geographic Channel, Casey Anderson. El videojuego está compuesto por ocho episodios en HD, de aproximadamente 30 minutos cada uno, con una serie de mini juegos que permitirán al jugador hacer uso del sensor Kinect y demostrar lo aprendido de una forma divertida e interactiva.

\section{Little Big Planet}

El juego hace uso de un poderoso motor físico para crear su propio contenido, como por ejemplo, ubicar etiquetas adhesivas en los niveles. Asimismo, se puede utilizar el editor de niveles 
para crearlos, destruirlos, editarlos y manipularlos $y$, finalmente, compartir dichas creaciones con la comunidad en línea y después jugar con los niveles creados por el propio usuario con otros.

\section{Disneyland Adventures}

Este juego ha llegado para enseñar a los niños cómo es un día en Disneyland y que puedan vivirlo una y otra vez desde sus casas gracias a Kinect. En el juego se recorre el enorme parque, encontrando los 35 personajes de las películas de la factoría Disney. Al pararse delante de alguno de ellos y saludarlos, literalmente puede acceder a interactuar con el personaje. A cada personaje se le puede pedir un autógrafo para completar el libro dedicado a ellos, chocar los 5, abrazarlo o bailar con él. Además, se podrá acceder a las diversas mini aventuras o misiones de lo más variopintas y que encajan con la personalidad o el mundo de la película en la que se basa.

\section{E. Constant C}

Juego de plataformas y rompecabezas protagonizado por un pequeño robot al que se le debe ayudar a superar un sinfín de desafíos en niveles 2D. Constant $C$ es una aventura que aumenta de forma considerable su nivel de dificultad de forma muy acusada a partir de cierto momento, hasta tal punto que solo la finalizarán un selecto grupo de jugadores: los más expertos $y$, también, pacientes.

TABLA I

Información Básica de Videojuegos Similares. Fuente: Propia.

\begin{tabular}{|c|c|c|c|c|c|c|c|}
\hline Nombre & Desarrollador & Edad & Plataforma & Genero & Formato & $\begin{array}{l}\text { Unidades } \\
\text { Vendidas } \\
\text { Global }\end{array}$ & Valoración \\
\hline LittleBigPlanet & $\begin{array}{l}\text { Media } \\
\text { Molecule }\end{array}$ & 7 & $\begin{array}{l}\text { PlayStation } \\
3 \text { PSP PS } \\
\text { Vita }\end{array}$ & $\begin{array}{l}\text { Plata- } \\
\text { formas } \\
\text { Creatividad } \\
\text { Lógica }\end{array}$ & $\begin{array}{l}\text { Blu Ray } \\
\text { Disc, } \\
\text { Descar- } \\
\text { ga de PS } \\
\text { Store. }\end{array}$ & $\begin{array}{l}5.90 \text { millones } \\
\text { de unidades. }\end{array}$ & 8,7 \\
\hline $\begin{array}{l}\text { Kinect: } \\
\text { Disneyland } \\
\text { Adventures }\end{array}$ & $\begin{array}{l}\text { Frontier DEV } \\
\text { LTD }\end{array}$ & 7 & $\begin{array}{l}\text { XBOX } 360 \\
\text { Con Kinect }\end{array}$ & $\begin{array}{l}\text { Mundo } \\
\text { Abierto, } \\
\text { Paseo } \\
\text { Virtual }\end{array}$ & DVD & $\begin{array}{l}2.37 \text { millones } \\
\text { de unidades. }\end{array}$ & 7,0 \\
\hline Constant C & $\begin{array}{l}\text { IGS (Interna- } \\
\text { tional Game } \\
\text { System CO } \\
\text { LTD) }\end{array}$ & 7 & $\begin{array}{l}\mathrm{PC} / \mathrm{XBOX} \\
360\end{array}$ & $\begin{array}{l}\text { Puzzle, } \\
\text { Platafor- } \\
\text { mas }\end{array}$ & $\begin{array}{l}\text { Des- } \\
\text { carga } \\
\text { Digital } \\
\text { XBOX } \\
\text { Live }\end{array}$ & $\begin{array}{l}\text { Inf. No } \\
\text { Disponible }\end{array}$ & 7,0 \\
\hline $\begin{array}{l}\text { Kinect Nat } \\
\text { Geo TV }\end{array}$ & $\begin{array}{l}\text { Relentless } \\
\text { Software }\end{array}$ & 7 & XBOX 360 & Acción & DVD & $\begin{array}{l}\text { Inf. No } \\
\text { Disponible }\end{array}$ & 7,8 \\
\hline $\begin{array}{l}\text { Kinect Sesame } \\
\text { Street }\end{array}$ & $\begin{array}{l}\text { Microsoft } \\
\text { Studios }\end{array}$ & 3 & XBOX 360 & $\begin{array}{l}\text { Educacio- } \\
\text { nal }\end{array}$ & DVD & $\begin{array}{l}\text { Inf. No } \\
\text { Disponible }\end{array}$ & 6,5 \\
\hline
\end{tabular}




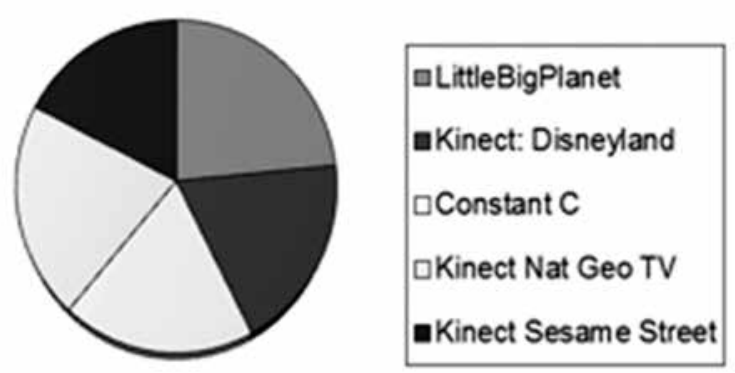

Fig. 1 Valoración Páginas Web Especializadas en Videojuegos.



Fig. 2 Edades para Cada Videojuego Según la Calificación Europea PEGI.

El video juego educativo desarrollado presenta una diferencia innovadora, ya que se realizó pensando en la educación de niños con edades tanto de la primera infancia (5 y 6 años) como de la segunda (7 a 10 años), inicialmente con un juego sencillo matemático para aprender a contar, y que puede ser ampliado en trabajos futuros a las diferentes áreas del conocimiento humano (Biología, Arte, Lenguaje, Informática..), manteniendo el concepto de generar actividades sencillas para el

\section{Meta Proceso Desarrollo de Software}

El meta proceso de software propone caracterizar una metodología desde la gestión, estructuración e innovación. Estos procesos corresponden respectivamente a la administración, arquitectura y creación de rasgos para el proceso de software [7]. prendizaje, con un valor que enriquezca la mente del infante y promueva su desarrollo.

\section{A. Gestión}

Aquí se definen los participantes, permitiendo identificar con claridad las fuentes de información, personas involucradas en el proceso de software e identificar igualmente quiénes no son de relevancia, eliminando el ruido que puedan introducir. La trazabilidad es una característica fundamental, pues define cómo los artefactos que se originan en el proceso van poco a poco evolucionando con cada fase en un artefacto más elaborado. Por ejemplo, un requerimiento se convierte en una funcionalidad y esta a su vez en una pieza de software, etc. [7].

\section{B. Estructuración}

La estructura permite dentro del proceso definir los bloques de construcción del mismo y cómo estos interactúan. Definir la arquitectura del proceso es importante para tener el mapa del proceso. Poder estructurar un proceso permite resolver dos preguntas fundamentales: ¿cómo actúa el proceso? y ¿por qué un proceso actúa de una forma determinada?

La estructuración permite la personalización del proceso, ya que este no debe ser un guion estático, más bien debe ajustarse a las condiciones del problema, de los participantes, de los recursos y de todas las variables que lo afecten. En este caso, se optó por utilizar el modelo en cascada, un modelo ya definido. Sin embargo, el proceso que condujo a él no lo es, por lo tanto se está haciendo meta proceso. Usar un mismo proceso una y otra vez puede ser nocivo; no buscar nuevas formas de resolver un problema a la postre creará limitaciones cuando el problema cambie y se vuelva más complejo o sea simplemente un nuevo problema.

\section{Innovación}

El otro enfoque del meta proceso está dado en la innovación, es necesario que los procesos 
establezcan formas en las que constantemente se reinventen, incluso se establezcan nuevas estrategias, mecanismos y pautas. La comunicación, el intercambio de conocimiento, verificación de la mejora y establecimiento de los incidentes típicos dentro de los procesos [7].

A continuación se presentan los pasos que se siguieron para llegar al producto final:

- Se instaló el siguiente software en el PC (EI PCdebe cumplir con los requerimientos establecidos en la sección de Hardware):

SDK Kinect 1.6.

Visual Studio 2010. XNA Framework 4.0.

Autodesk 3D Max 2016.

Photoshop CS.

- De acuerdo con la idea para el desarrollo del video juego educativo para niños de 5 a 10 años de edad, se realizó una búsqueda en internet de los recursos necesarios para el proyecto, como lo son: imágenes, modelos 3D, música y tipos de fuentes (de uso libre para utilizar en proyectos en caso de no ser de propia autoría).

- Se realizaron lecturas de varios libros referentes a la programación en C\#, Kinect y XNA Framework. Se ubicaronn versiones generalmente en inglés, en formato PDF, con ejemplos de código para su estudio y aplicación en otros proyectos.

- Se utilizó el software Autodesk 3D Max para realizar las modificaciones necesarias a los modelos 3D descargados de internet (cambio de proporciones en el modelo, retirar las partes que no son necesarias, cambio de colores, adición de otros modelos, etc.) o crear modelos propios. Se exportaron a la carpeta Content en formato FBX, ya que XNA Framework 4.0 solo trabaja modelos 3D con esta extensión.

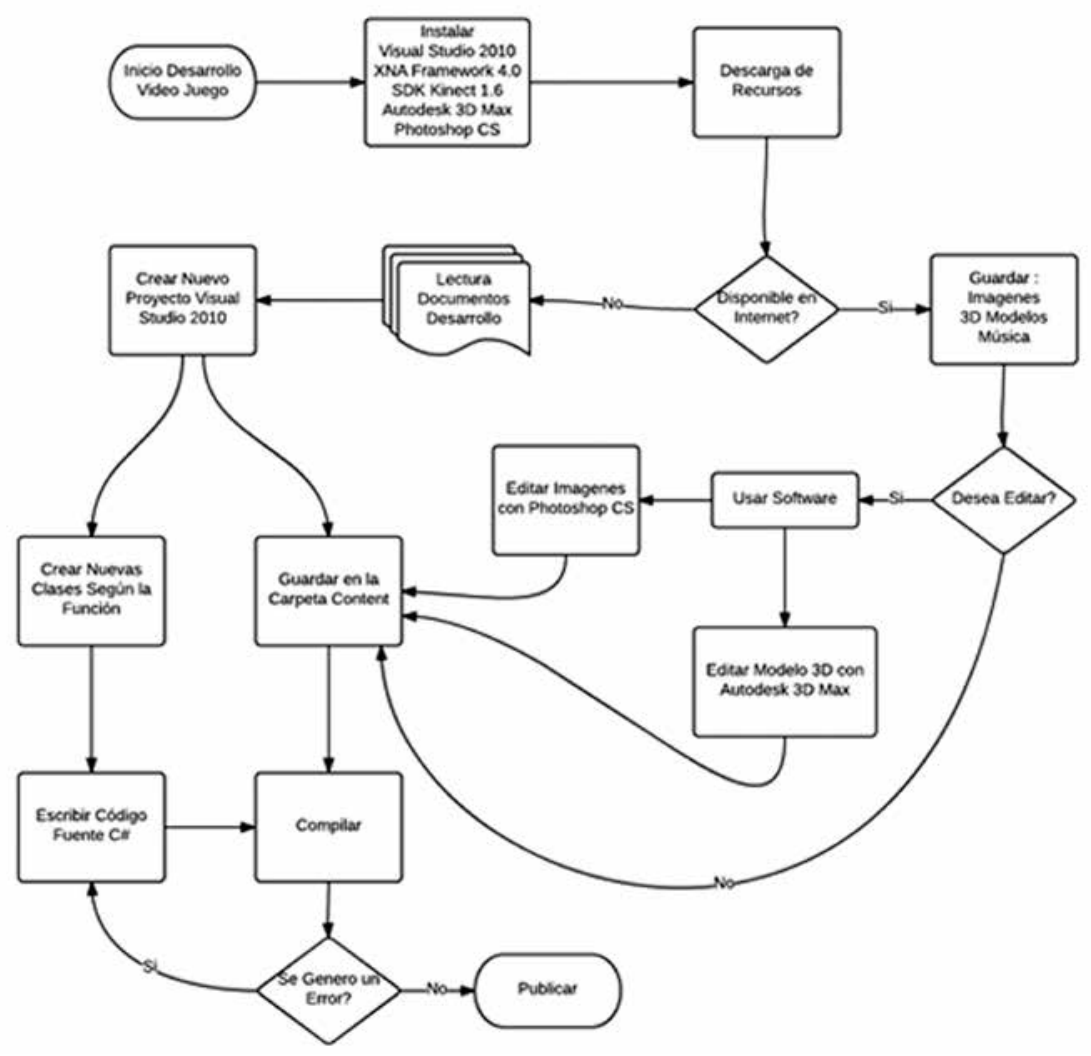

Fig. 3 Diagrama Flujo de Procesos 
- El software Photoshop CS es necesario para realizar modificaciones a las imágenes de acuerdo con el proyecto, permitiendo combinar varias de ellas y adicionar textos, todo por medio de capas. Se guardaron en la carpeta Content en formatos PNG y JPG acorde con tipo de imagen requerida.

- Se creó un nuevo proyecto en Visual Studio 2010 “Windows Game 4.0 - Visual C\#, se le dio un nombre y así se generó un proyecto que contiene una clase principal "Game1.cs" junto a otros archivos y carpetas que se generan automáticamente como parte del proyecto. Una carpeta importante es la de "Content”; en ella se crearán nuevas carpetas de acuerdo con los recursos que se utilizarán en el proyecto. Por ejemplo, la carpeta "Música" que contendrá las canciones en formato $\mathrm{mp} 3$ acorde con el juego; la carpeta "Modelos" para los modelos 3D en formato FBX y la carpeta "Botones" para las imágenes en formato PNG referente a los botones que tendrán una acción concreta.

- En el área donde se ubica el archivo Game1. cs, también se generarán nuevas carpetas que contendrán las nuevas clases creadas, acordes con la función que desarrollará cada una en el video juego. con el fin de llevar un orden en el proyecto. Ejemplo de esto, es la carpeta "Auxiliares" que contiene las clases AnimacionManos.cs (maneja la animación de las manos cuando se ubica sobre un objeto activable) y TexturaAnimada.cs (dibuja en pantalla la textura relacionada a la precarga de la animación de las manos). Otra carpeta creada es "Kinect"con las clases referentes al reconocimiento por parte del dispositivo Kinect de los gestos y esqueletos (GesturesK.cs y UserKinect.cs). Aquí solo estará contenido todo el código fuente necesario para el funcionamiento lógico del video juego.
- Ir compilando el proyecto con el fin de verificar su funcionamiento y revisar los posibles errores que se presenten, realizando las correcciones oportunas al código fuente.

- Finalmente, después de terminado el proyecto, se publica, lo cual genera el instalador de la aplicación [3].

\section{Resultados del Desarrollo}

Después de llevar a cabo la metodologia propuesta, se desarrolló y se obtuvo como producto final un videojuego educativo funcional con el dispositivo Kinect. Opcionalmente, en caso de no disponer de este periférico, el teclado y mouse del computador se ofrecen como herramientas alternativas para la interacción del usuario con el aplicativo [3].

A continuación se presentan algunas imágenes con su explicación, sacadas directamente del producto obtenido, gracias al análisis y desarrollo mencionados anteriormente en este articulo:

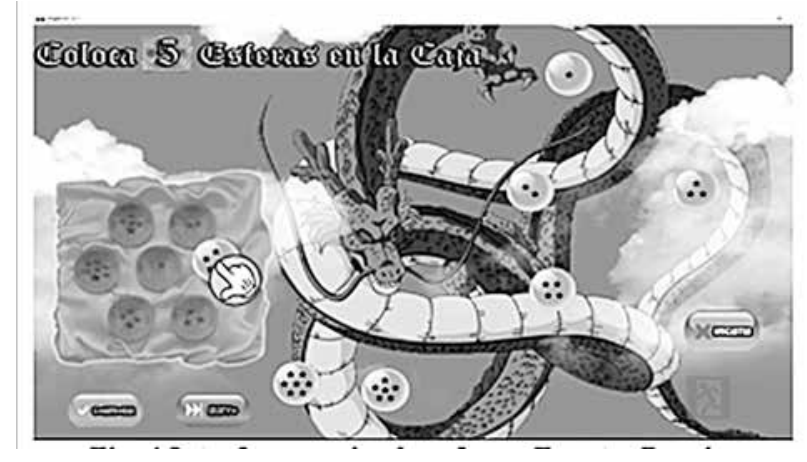

Fig. 4 Interface moviendo esferas.

En la figura 4 se presenta la interfaz gráfica en $2 \mathrm{D}$ del video juego de contar esferas. Se observa en la parte superior la cantidad de esferas solicitadas, las cuales deben ser movidas con la manita animada al cojín, pasando exactamente la cantidad solicitada y luego evaluando con el botón "comprobar" si es correcta la cantidad o no. 


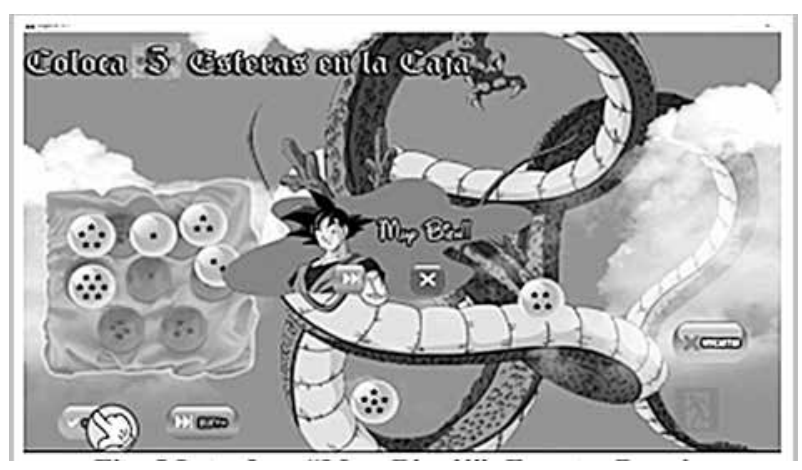

Fig. 5 Interface “Muy Bien!!”.

En la figura 5, la interface enseña una de las ventanas emergentes al momento de hacer la comprobación de la cantidad de esferas pasadas al cojín. Si está correcto saldrá el mensaje "Muy Bien!!", con un botón que indica un nuevo juego y otro botón para cerrar la ventana. De igual forma, al lado del botón "comprobar" se encuentran el botón "Nuevo" que permite probar otras cantidades de esferas por mover, y el botón "Deshacer", que permite regresar una esfera a su lugar original, con solo arrastrarla hasta el botón por unos segundos.

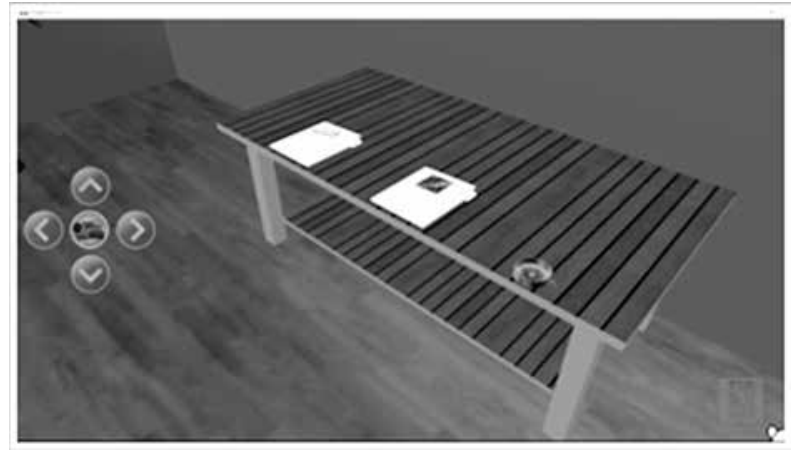

Fig. 6 Objetos seleccionables.

En la figura 6, se pueden observar tres elementos sobre una mesa: dos carpetas y una brújula. Cada uno permite el acceso a una serie de diapositivas con información referente a la historia del juego... ¿Qué se pretende hacer en el juego? Otra opción que se encuentra, son los créditos de cada objeto, imagen o música que contiene el video juego, al igual que los créditos de desarrollo del mismo. Finalmente, las instrucciones para interactuar con el juego, con ayuda del dispositivo Kinect o en caso de no contar con este, con el teclado y mouse como opción alternativa.

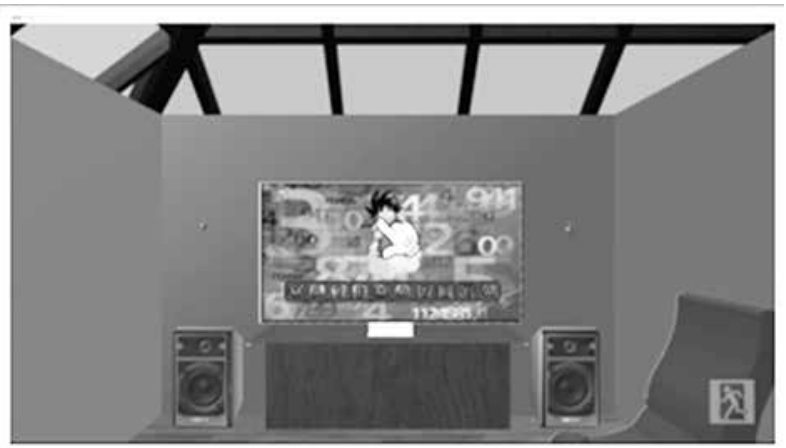

Fig. 7 Interface habitación 3D.

En la figura 7, se observa parte de la habitación en 3D, la cual contiene una serie de modelos decorativos, algunos de ellos activables e interactivos utilizando las manitas animadas que responden al movimiento de las manos frente al dispositivo Kinect; de la misma forma, se avanza por la habitación moviendo el pie derecho al frente o atrás.

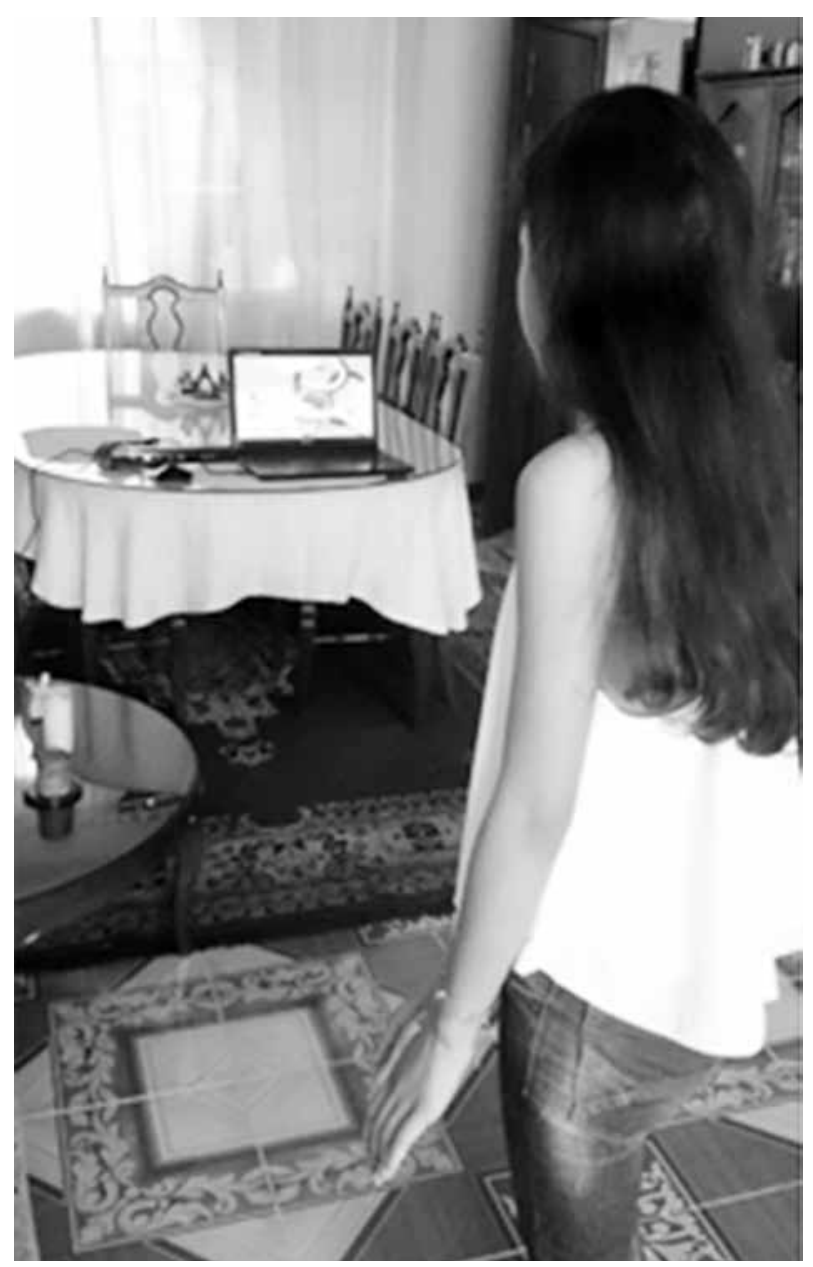

Fig. 8 Niña de 10 años jugando. 


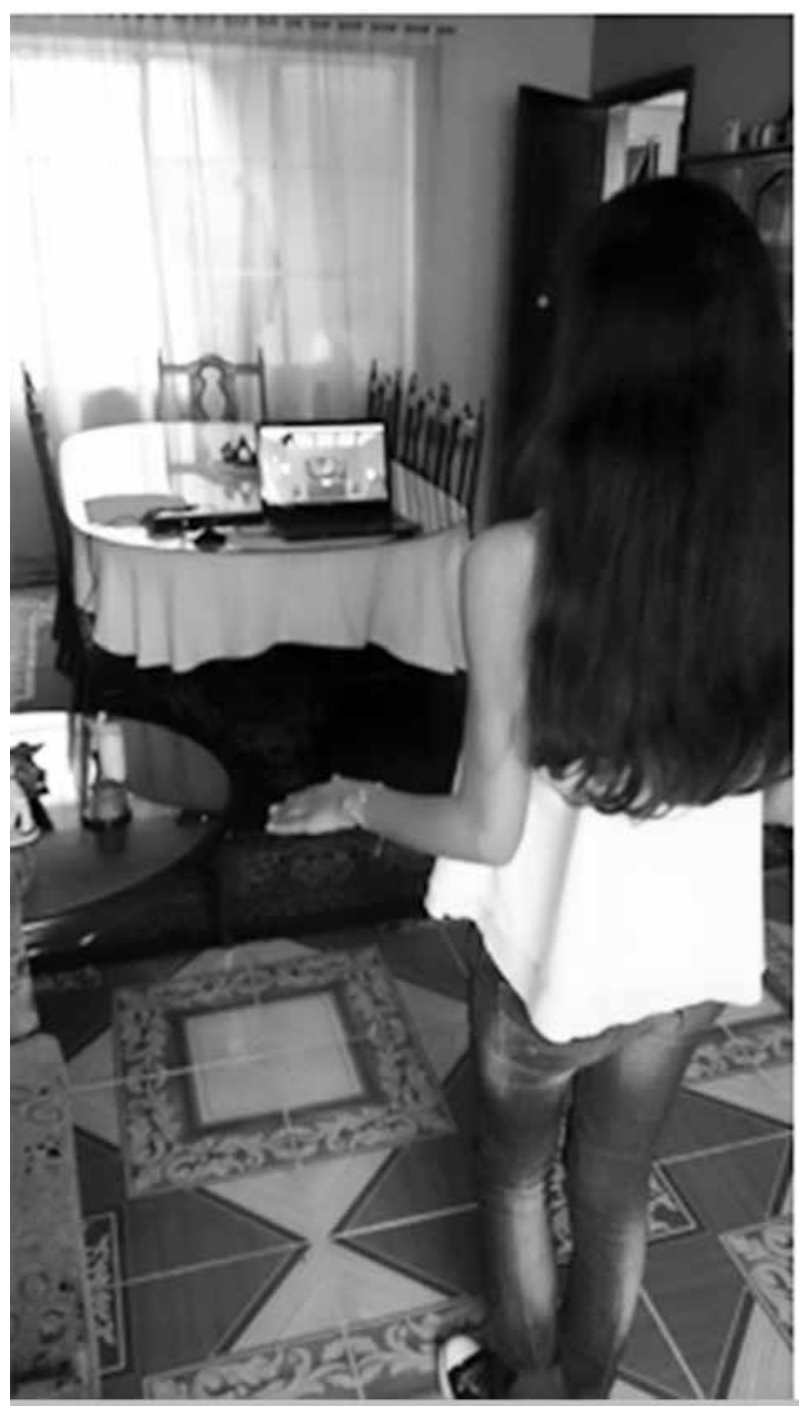

Fig. 9 Niña de 10 Años Jugando.

En las figuras 8 y 9, una niña de 10 años prueba el video juego educativo, desarrollado con las herramientas mencionadas en apartados anteriores, utilizando el dispositivo Kinect conectado al PC.

\section{Conclusiones Y Trabajo Futuro}

La implementación de recursos pedagógicos innovadores como son juegos educativos y herramientas tecnológicas para las diferentes asignaturas, genera en el alumnado una serie de ventajas, entre otras, captar su atención y generar en ellos el deseo de ser partícipes activos de las actividades que con dichas herramientas se desarrollen.

Los videojuegos en la escuela primaria fomentan las relaciones sociales y morales, y son agentes de transmisión de ideas. Por lo anterior, es muy importante ampliar los módulos para el estudio de otras asignaturas como inglés, de gran importancia en la educación de todo ser humano para ser competitivo profesionalmente, y abrir nuevos caminos culturales en el mundo. Así mismo, pueden estar relacionados con las Ciencias Naturales, para apoyar al niño en el conocimiento del método científico y el estudio de la naturaleza y sus aspectos físicos, así como con el desarrollo del pensamiento lógico - matemático.

El profesor y el padre de familia necesitan evaluar el avance de los niños en su desarrollo y adquisición de conocimientos. Es de valor agregado, adicionar una sencilla base de datos en un trabajo futuro, que permita almacenar el nombre del niño y los puntajes que logre acumular en el desarrollo de cada actividad propuesta, con el fin de obtener tablas estadísticas que permitan observar y evaluar sus cambios ya sean positivos o negativos.

A partir de lo expuesto anteriormente, se concluye que los videojuegos educativos aumentan la disposición hacia el estudio de diferentes asignaturas, cambiando de esta manera la visión de la educación que los alumnos poseen. Es importante mantener una interacción con el videojuego de tal forma que el usuario se sienta a gusto con la actividad que realiza en el mismo, para lo cual la Interacción Humano Computadora es un paso fundamental para establecer el acoplamiento correcto por medio del dispositivo Kinect y tener como alternativa el uso del Teclado y Mouse para no limitar el acceso. 


\section{REFERENCIAS}

[1] Plan Sectorial 2010-2014 Documento $\mathrm{N}^{\circ}$ 9, [Online]. Disponible: www.mineducacion.gov.co

[2] El Espectador, Educación, Preocupantes Cifras de Deserción Escolar (25 Sept 2014) [Online]. Disponible: http://www.elespectador.com/noticias/educacion/preocupantes-cifras-de-desercion-escolar-articulo-518837.

[3] J. H. Tangarife, "KIGAME", Derechos de Autor 13-53259, Mayo 16, 2016

[4] Musen, Coger \& Kagan. Desarrollo de la personalidad en el niño. México: Trillas.1972.
[5] Latín (2014). Temas de Diseño en Interacción Humano - Computadora. [Online]. Disponible: http:// latinproject.org/books/Temas_de_Dise\%C3\%B10_ en_Interacci\%C3\%B3n_Humano_Computadora_CC_ BY-SA_3.0.pdf

[6] Galeano, R. (2008, Junio 12). Diseño Centrado en el Usuario. Revista $Q$ (Artículo de Investigación Académica, Científica y Tecnológica), 3. [Online]. Disponible: http://revistaq.upb.edu.co

[7] S. J. Castro, V. H. García y J. S. Carrión, "Marco conceptual para el meta proceso de desarrollo de software," Universidad Distrital Francisco José de caldas, Agosto 3-5, 2011. 